\title{
Quantitative Measurable Concepts to Visualize Business Process Improvement
}

\author{
Oluwatoyin Fakorede \\ Department of Computing and \\ Informatics \\ Faculty of Science and Technology, \\ Bournemouth University \\ United Kingdom \\ $+441202965627$ \\ ofakorede@bournemouth.ac.uk
}

\author{
Philip Davies \\ Department of Computing and \\ Informatics \\ Faculty of Science and Technology, \\ Bournemouth University \\ United Kingdom \\ $+441202965560$ \\ daviesp@bournemouth.ac.uk
}

\begin{abstract}
Business process improvement evaluation enables performance indicators to be used alongside process improvement techniques in order to quantitatively compare measurement information between the as-is and to-be processes. Limitations of the present methods of business process improvement indicate there is scope for looking at the problem in a different way. Business processes are commonly modelled as diagrams which at their fundamental level are complex networks. This suggests the question as to whether complex network analysis (CNA) has anything to contribute to business process improvement. We develop a technique of projecting a business process model onto the sub-space of a complex network and identify the measurable concepts that can be useful in business process improvement. The measurable concepts from CNA are combined with Time and Cost metrics from the simulation technique to visualize and track improvement efforts and satisfy improvement requirements.
\end{abstract}

\section{CCS Concepts}

- Applied Computing $\rightarrow$ Enterprise computing $\bullet$ Business process management $\rightarrow$ Business process modeling.

\section{Keywords}

Process modeling; measurable concepts; business process improvement; BPMN; complex network analysis.

\section{INTRODUCTION}

The need for organizations to maintain good quality service levels, balanced resource utilization, quick response times, adaptation to market changes and customer demands, healthy staff and customer satisfaction, time and cost savings and to continually be at a competitive advantage necessitates the need for continuous process analysis. A business process is analyzed both at design time and run time to find design flaws and diagnose support needs respectively [1]. Process analysis facilitates the identification of issues within the current (as-is) business process and ensures that they do not reoccur in the proposed (to-be) process. It also identifies bottlenecks, non-value adding activities and generates process alternatives [2], [3]. A well-engineered business process employs measures to monitor and guide process performance in a desired direction. Therefore, for an organization to attain maturity in their processes, measurements must be integrated into business improvement objectives [4]. Measures can be applied during the design stage of the process development to capture the static properties (complexity, density, cohesion etc.) of the business process. Measures can also be applied at execution stage to quantify the dynamic properties (cycle time, cost etc.) of the business process. Together these can be used to compare the result of the as-is with the to-be processes to ascertain how much improvement has been achieved within a specific time frame. These measures are presented in Table 1 .

Table 1. Design and Execution Time Measures [4]

\begin{tabular}{|l|l|}
\hline $\begin{array}{l}\text { Design Time } \\
\text { Measures }\end{array}$ & $\begin{array}{l}\text { Execution Time } \\
\text { Measures }\end{array}$ \\
\hline Complexity & Functionality \\
\hline Quality & Quality \\
\hline Coupling & Usability \\
\hline Entropy & Reliability \\
\hline Density & Effectiveness \\
\hline Cohesion & Efficiency \\
\hline Modifiability & Cycle time \\
\hline
\end{tabular}

Most of the measures in Table 1 are adapted from software engineering but many of them lack empirical validation [4][5]. There is no standard set of metrics that can be used to measure improvement. Other authors have favored metrics such as quality [6], complexity [7], the Quadrangle comprising of Time, Cost, Quality and Flexibility [8]. 
Unfortunately, there is no agreement on appropriate approaches to measure process improvement.

This paper is therefore concerned with the question: What metrics are appropriate for quantitatively measuring process improvement both at design and execution stages?

One commonly used but hard to define metric is quality [5], as a measure quality is multidimensional and multifaceted and should be quantified using multiple measures. Internal quality measures (density, coupling, complexity etc.) influence external quality measures (understandability, usability, and modifiability etc.) and the relationships are not straightforward. Internal quality measures can proffer insight into the macroscopic properties such as the strength or quality of the relationship between the activities in the model [9]. Existing traditional business process analysis techniques cannot assess the structural properties of a business process model [8], [10]; therefore, a complex network analysis approach is employed to analyze the structural relationship and behavioral structure of the process activities.

Business processes are commonly modelled as diagrams which at their fundamental level are complex networks of nodes and links. The performance of a process is affected by its network structure in a non-trivial way. For example, in road traffic, alternative routes will result in fewer traffic jams, although the alternative route is not necessary the fastest. Road construction engineers conduct traffic impact simulations for road construction projects, policy setting and traffic organization [11]. Therefore, metrics which have an influence on process flow such as 'shortest path' in complex network analysis may be useful for assessing more efficient processes.

In order to apply the complex network analysis approach, business process models are projected onto a sub-space of networks and quantitative measures are obtained relating to their intrinsic structure. We propose that the combination of complex network analysis coupled to simulation approaches can provide quantitative measures of process improvement both at design and execution stages.

The remainder of this paper is structured as follows: Section 2 describes the background to the concepts. Section 3 presents our approach for analyzing and measuring business process models and selection of metrics. The subsequent sections present the simulation technique for performance analysis of a business case study, implementation of the simulation methodology, network projection of the business

SAMPLE: Permission to make digital or hard copies of all or part of this work for personal or classroom use is granted without fee provided that copies are not made or distributed for profit or commercial advantage and that copies bear this notice and the full citation on the first page. To copy otherwise, or republish, to post on servers or to redistribute to lists, requires prior specific permission and/or a fee.

Conference'10, Month 1-2, 2010, City, State, Country. Copyright 2010 ACM 1-58113-000-0/00/0010 ...\$15.00. DOI: http://dx.doi.org/10.1145/12345.67890 process models and visualization of the results. Finally, section 6 presents the conclusion and future work.

\section{PREVIOUS METRIC PROPOSALS}

The determination of process improvement is focused on the correct choice and combination of metrics. Much work has been devoted to this area and there has been a long succession of attempts at defining the best measures. Rolon et al. [12] define a set of metrics for the evaluation of the complexity of conceptual models of business processes based on the adaptation and extension of the FMESP (Framework for the Modelling and Evaluation of Software Processes). The work was unvalidated and inconclusive. Gonzalez et al [4] examined a number of measures and concluded that there is lack of measurement validation and most authors do not place importance upon validating activities. Others have proposed measures specific to standard languages such as Event-driven Process Chain (EPC), BPMN, YAWL, Petri net, UML AD [11], [12].

Bisogno et al. [15] provide a method for detecting process criticalities and identifying the best corrective actions using BPMN and Business Processes Simulation to measure key performance indicators using criteria such as completion rate of process, throughput time, rate of resource utilization and resources service level. The outcome of the study needed further refinement. Given that simulation models can be time consuming and costly, financial costs should have been included as part of the indicators.

Jamila et al. [16] proposed an approach that uses existing quality metrics to evaluate the quality of BP models in terms of comprehensibility or understandability and modifiability or flexibility such as:

Control Flow Complexity (CFC): Complexity is a measure of simplicity and comprehensibility of the process model.

Cardoso et al. [17] adapted McCabe's cyclomatic number [18] as a complexity metric for CFC which takes into account the number of gates, (AND, OR, and XOR etc.) and counts the number of decisions in the flow of control. The number of all possible decisions is increased by every split in the model.

Other metrics proposed include: Interface Complexity (IC), Number of Activities (NOA), Number of Activities, Joins and Splits (NOAJS), and Coefficient of Network Complexity (CNC). CNC is the ratio of the total number of links in a process model compared to its total number of nodes.

Vanderfeesten et al. [19][20] has defined Cross Connectivity (CC) to measure the strength of the arcs between process model nodes and a Coupling metric (CP) which is the number of interlinks between the activities of a process model. The degree of coupling is dependent on the type of gateways (AND, OR, XOR) between activities and the complexity of the connections. Density (D) was defined 
by Mendling [21] as the total number of links compared to the maximum number of links. Their approach was validated by developing a BP-Quality tool, but no information was provided about the interpretation and applicability of these metrics.

Consideration of these metrics leads to the conclusion that the use of software metrics is considered a useful approach to measuring business process models during design time and can be used to measure improvements.

Table 2 Relevant Complex Network Analysis Metrics

\begin{tabular}{|l|l|l|}
\hline Measures & Description & Relevance/Interpretation \\
\hline Size & $\begin{array}{l}\text { It measures the } \\
\text { number of nodes or } \\
\text { activities in the } \\
\text { model [7]. }\end{array}$ & $\begin{array}{l}\text { Measures structural } \\
\text { complexity. }\end{array}$ \\
\hline Diameter & $\begin{array}{l}\text { The longest } \\
\text { geodesic path in } \\
\text { the network. }\end{array}$ & $\begin{array}{l}\text { It can be used as a metric for } \\
\text { network size or complexity. } \\
\text { The higher the diameter, the } \\
\text { higher the complexity. }\end{array}$ \\
\hline Density & $\begin{array}{l}\text { The ratio of links } \\
\text { present in the } \\
\text { network and the } \\
\text { maximum number } \\
\text { of possible links. }\end{array}$ & $\begin{array}{l}\text { It can be used to test the } \\
\text { modifiability or flexibility of } \\
\text { a business process when } \\
\text { changes are made. }\end{array}$ \\
\hline
\end{tabular}

Some of these metrics (such as the CFC, NOA) can be determined from formula, while others require the use of software tools. Even when the measures were obtained as described above, there is no concrete interpretation in direct relation to the process model.

We are therefore proposing a new approach which is based on a consideration of the underlying network structure of the business processes using complex network approaches.

\section{COMPLEX NETWORK ANALYSIS}

A network is a group of nodes and links often referred to as a graph in mathematical literature [22] [23]. In this paper, the term network, node and links are used throughout. The pattern of the relationship between these nodes can be identified and measured using network theory [24]. We project a business process model designed in BPMN onto a directed network. A directed network is preferred (over undirected) as this portrays the directed nature of the connection between most business processes.

\subsection{Rules for Projection}

We adopt the idea of "levels of abstraction" to move from a low-level detailed business process model to a high-level network structure where some elements in the process model are removed. We present an algorithm for reducing a process model to its basic structure (projective space) for analysis:

1) Activities become nodes, and information flows (message flows) and material flows become links.
2) Identify the right level of Analysis because business processes can be analyzed at different levels such as [25]:

\section{Figure 1. Modified Quadrangle [26]}

a) Individual level: analysis is based on a node and its relations

b) Dyad: Relationship formed by a pair of nodes

c) Triad: Relationship among three nodes

d) Complete Network: Relationship between all the nodes in the network. This is our preferred level of analysis.

3) Gateways, Pools and Lanes details are not considered because there are no elements in network diagrams to represent these.

4) Notes, pictures, or document links containing extra information are not included.

5) Sub-processes can be modelled as sub-networks but will not be considered in the main network.

6) Decide on the type of relationship that exists between nodes. In our case, we use the directed network

7) Start and end nodes are not included. Databases and other systems are not included.

\subsection{Complex Network Analysis Metrics}

The study of the nature of links in a network can help give insight into the characteristics of the network. These characteristics are assessed using network metrics i.e. the metrics that can be used to quantitatively analyze the structure of a network. Table 2 shows the description of relevant metrics and their interpretation with respect to business process model.

\subsection{Metric Selection - The Quadrangle}

Brand and Van der Kolk [26] describe the effects of process improvement activities on the metrics of time, cost, quality and flexibility charted along four dependent dimensions displayed as a quadrangle. However, quality as previously discussed is a complex multivariate quantity that cannot be easily defined. In this paper, we replace quality with complexity as shown in Figure 1. Brand and Van der Kolk's model does not have independent quantities and is structured so that an improvement in one dimension could have a negative impact on another. Thus, a reduction in delivery time could increase costs, for instance to hire more people to

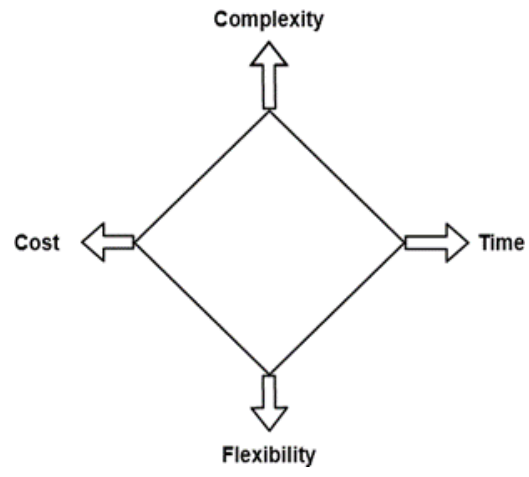


facilitate a quicker process. This is an expectation of the way that many systems work.

This means that modelling a complex system with dependent parameters is not straightforward which may also be connected in ways which are unpredictable and there may be unforeseen connections at a deep and undiscoverable level.

Consequently, a relative approach is proposed here which in the first instance assumes independence between our four metrics of [5], [8]:

- Cost: Operational cost especially cost related to human resources required in producing a good or delivering a service,

- Time: Throughput time required to handle a case from start to finish,

- Complexity: The number of components and their relationships,

- Flexibility: The degree to which a model can be effectively and efficiently modified without introducing defects or diminishing quality.

These metrics are deployed independently but used relatively for both the as-is and to-be models. By measuring the difference in volume from the as-is to the to-be models, we can say that an overall decrease in the volume of the phase space quadrangle is a measure of the improvement of the system. An interdependency of parameters is not an issue because it is the relative change in volume that counts not the absolute volume. It is not necessary in this model to account for the possible interconnections between parameters to determine if an improvement has been obtained. The only need is to look for an overall decrease in volume of the phase space as a measure of efficiency.

In order to accommodate this, each axis is treated independently and the negative polarities of the Cost-axis and Flexibility-axis are ignored, for instance a decrease in cost would mean the point plot of the graph will move inward instead of moving outward (contrary to the behavior of the negative $\mathrm{X}$-axis). The flexibility dimension also has reverse polarity and scale because an increase in flexibility is an improvement. This is illustrated in Figure 2.

Thus, if the measured outputs are used, regardless of their dependence or independence it can be inferred that a reduction in phase space volume is a measure of improved efficiency. The intention here is not to model how the system works but how to measure improvements in the system and for that we do not need to know how one dimension might impact on another. Of course, changing one parameter may affect the others but that is an internal consideration of the particular process. All that need be said in this model is that if changes are made and a reduction is visible then the process has been improved.

With regards to the scale used for each independent metric, it is noted that Time is measured in seconds and the scale is marked at intervals of 500 . But this relative to the business process. It could be measured in minutes or hours depending on the process. Cost is measured in thousands but again the scale is relative to the particular process. Complexity is 1:5 and Flexibility is 1:5. The unit for time is seconds, cost is dollars, flexibility and complexity are measures generated by complex network analysis and since they are units of phase space rather than real quantities, they do not have any correspondence to real space units and can be considered numerical only. The scale is generated by the max and min values coming from the complex network analysis metrics. However, scale is not important since we are only dealing with relative quantities. The goal is not to compare the metrics to each other, (so scale normalization will not be required) the goal is to compare the volume of the overall metric in the quadrangle of the as-is model to that of the tobe model. The relative volume measure means that absolute scale values are not significant for our optimization process.

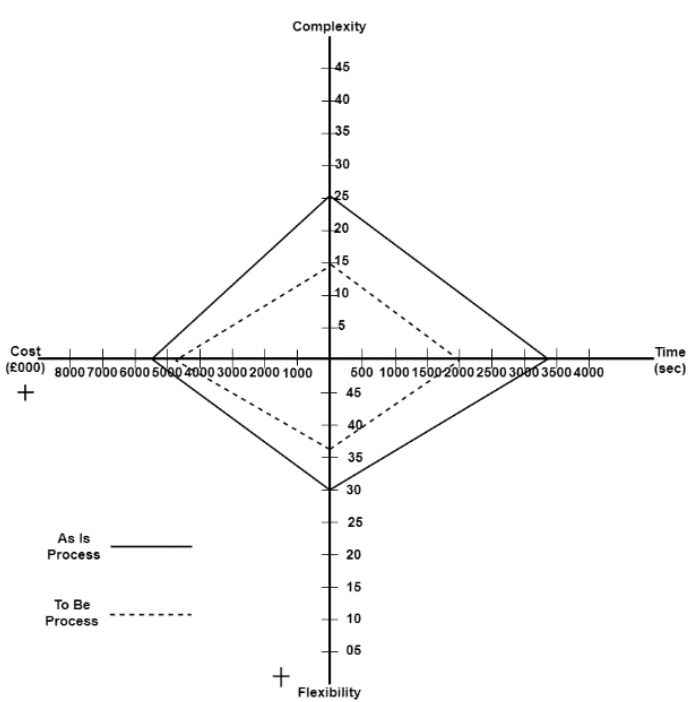

Figure 2. Scaled Reversed-Y Quadrangle

The 4 metrics are determined by measures taken from domains of simulation analysis and Complex Network Analysis and these are related to the metrics as shown in Table 3.

Table 3. Metrics Classification

\begin{tabular}{|l|l|l|l|}
\hline No & Metric & Domain & Measure used \\
\hline 1 & Time & Simulation & Cycle Time \\
\hline 2 & Cost & Simulation & Cost \\
\hline \multirow{2}{*}{3} & Complexity & $\begin{array}{l}\text { Logical } \\
\text { Complexity }\end{array}$ & $\begin{array}{l}\text { Control Flow Complexity } \\
\text { (CFC) }\end{array}$ \\
\cline { 3 - 4 } & & $\begin{array}{l}\text { Structural } \\
\text { Complexity }\end{array}$ & Size (s) and Diameter (d) \\
\hline 4 & Flexibility & $\begin{array}{l}\text { Structural } \\
\text { Flexibility }\end{array}$ & Inverse of Density (D) \\
\hline
\end{tabular}

1. Simulation domain: Quantitative measures that can be derived from simulation such as cycle time and cost. 
2. Logical domain: This considers the control flow aspect of the model by calculating the Control Flow Complexity (CFC) to measure the logical complexity of the process model.

3. Structural domain: This entails a complex networkoriented approach to analyze the structural properties and measure the structural complexity and flexibility of the process model. The structural complexity is defined as the average of the size and diameter of the network while the flexibility is defined as the inverse of the network density. The size, diameter and density of the metrics can be obtained by using the appropriate complex network analysis and visualization software tool [27].

As implied above, we consider complexity from two facets namely; logical complexity and the structural complexity. This is because the logical complexity only takes into consideration the decision nodes within the process model but does not give any information about the structural complexity. The logical complexity is determined by the control flow complexity (CFC) of the model, which is the sum of all the split AND, XOR and OR gateways. The structural complexity is determined by the average of the size and diameter of the network abstraction of the model.

The formulae for the CFC:

$$
\begin{aligned}
\mathrm{CFC}(\mathrm{BP})= & \sum_{\text {AND-split }} \mathrm{CFC}(\mathrm{C})+\sum_{\text {OR-Split }} \mathrm{CFC}(\mathrm{C})+ \\
& \sum_{X O R-\text { Split }} \mathrm{CFC}(\mathrm{C})
\end{aligned}
$$

Where

AND-split $=+\mathrm{n}$,

XOR-Split $=+n$,

OR-Split $=2^{n-1}$

We define the formulae for the structural complexity as:

$\mathrm{SC}=(\mathrm{s}+\mathrm{d}) / 2$,

We define the formulae for the overall complexity as:

$C=\frac{c f c+(\mathrm{s}+\mathrm{d}) / 2}{2}$,

Where

$c f c=$ control flow complexity,

$\mathrm{s}=$ size,

$\mathrm{d}=$ diameter.

We now turn to demonstrate an application of this method and present the simulation of the business case study in order to obtain measures in the time and cost dimensions.

\section{BUSINESS PROCESS SIMULATION}

Simulation technique allows performance analysis to be carried out on a process model which helps to detect flaws, bottlenecks and human resource planning [28]. We use the simulation modelling for reengineering collaboration in higher education methodology [29].

\subsection{Simulation Methodology}

The business case study used is the clearing process of a UK University, the details of the process are available in our previous paper [30]. The simulation modelling for reengineering collaboration in higher education methodology is implemented as follows:

\subsubsection{Step One: Initiation}

Using the Simulation mode provided by Bizagi, the model was configured (see table 4) based on the information obtained from admission staff and author's real experience.

\subsubsection{Step Two: Analysis}

The number of simulation instances was 500 representing 500 applicants. The Bizagi time analysis and resource analysis levels are configured as shown in the tables 5 and 6 while simulation result is shown in tables 7 and 8 .

\subsubsection{Step Three: Re-engineering}

The 'as-is' process model was analyzed, and some issues were identified and addressed in our previous work [30] this led to the creation of the to-be process model. When the university offers an applicant a place, this is accompanied by an offer letter emailed to the applicant and an upload of all offers to UCAS. A notification is sent to the student to either confirm or reject the offer. A tracking activity also runs in parallel to the offer decision notification from the applicant, ensuring that applicants can only select one offer at a time. Once the University downloads the offer confirmations, these can be processed and invitation for enrolment is sent to the applicant. As a result of the above modification, the activity "Contact Applicant" as shown in figure 4 would no longer be necessary because if an applicant does not confirm an offer, they must have accepted an offer elsewhere or no longer interested.

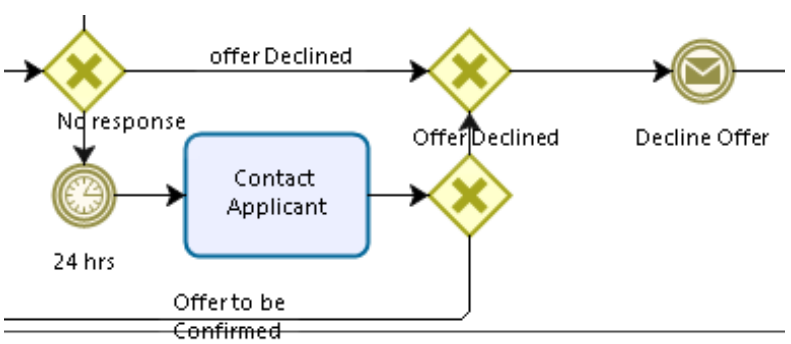

Figure 3. Removed 'Contact Applicant'

\subsubsection{Step Four: Implementation:}

The same simulation parameters used for the simulation of the 'As Is' process are used for the 'To Be' process. Table 9 shows the outcome of the simulation of both the 'As Is' and 'To Be' processes in the time and cost dimensions only. 


\subsubsection{Step Five: Evaluation}

An inefficient use of resources was identified in the 'contact applicant' activity and removed, this has had positive impact on cost and time saving. The time analysis for the as-is process in table 6 shows that the average time expended in contacting applicants is 1070.92 seconds ( $57 \mathrm{mins}$ ), this time is saved in the to-be process. Similarly, the resources analysis for the as-is process (table 8 ) shows a total cost of $£ 12,033.67$ while the resource analysis for the to-be process shows a total cost of $£ 7,251.33$, a saving of $£ 4,782.34$. From table 8 , there is an improvement in the 'To Be' clearing process in the time and cost dimension.

Table 4 Process Validation Configuration

\begin{tabular}{|l|l|l|}
\hline No & Process & Element \\
\hline 1 & UCAS & 500 tokens \\
\hline 2 & Applicant & $\begin{array}{l}\text { Applicant Reject Uni Offer 50\% } \\
\text { Applicant applies to Uni on UCAS } \\
\text { TRACK 50\% }\end{array}$ \\
\hline 3 & $\begin{array}{l}\text { Triage } \\
\text { Team }\end{array}$ & $\begin{array}{l}\text { No Place Available 5\% Transfer Call to } \\
\text { Department 95\% }\end{array}$ \\
\hline 4 & Department & $\begin{array}{l}\text { Refuse Offer 5\% } \\
\text { Place Offer 95\% }\end{array}$ \\
\hline 5 & Department & $\begin{array}{l}\text { No Response 10\% } \\
\text { Declined Offer 10\% Confirmed Offer } \\
80 \%\end{array}$ \\
\hline 6 & Department & $\begin{array}{l}\text { Declined Offer 20\% Confirmed Offer } \\
80 \%\end{array}$ \\
\hline
\end{tabular}

Table 5: Time Analysis Configuration

\begin{tabular}{|l|l|l|l|}
\hline No & Activity & $\begin{array}{l}\text { Processing } \\
\text { Time } \\
(\mathrm{min})\end{array}$ & $\begin{array}{l}\text { Waiting } \\
\text { Time } \\
(\mathrm{min})\end{array}$ \\
\hline 1 & Triage Call & 3 & 3 \\
\hline 2 & Chat with Applicant & 3 & 3 \\
\hline 3 & Place Offer & 3 & 0 \\
\hline 4 & Download Data & 1 & 0 \\
\hline 5 & Refuse Offer & 0 & 0 \\
\hline 6 & Processing Offer & 3 & 0 \\
\hline 7 & Contact Applicant & 3 & 0 \\
\hline 8 & Upload offer Conf. to UCAS & 1 & 0 \\
\hline 9 & $\begin{array}{l}\text { Send Enrolment Invitation to } \\
\text { Applicant }\end{array}$ & 1 & 0 \\
\hline
\end{tabular}

Table 6: Resource Configuration

\begin{tabular}{|l|l|l|l|l|}
\hline No & Resource & Quantity & Cost/hr & Total Hrs/day \\
\hline 1 & Triage Team & 4 & 10 & 34 \\
\hline 2 & Academics & 4 & 20 & 34 \\
\hline
\end{tabular}

Table 7: Resource utilization

\begin{tabular}{|l|l|l|l|}
\hline Resource & Utilization & Total unit cost & Total cost \\
\hline Triage Team & $90.91 \%$ & 4000 & 4000 \\
\hline Academics & $91.29 \%$ & 8033.666667 & 8033.666667 \\
\hline
\end{tabular}

Table 8: Time Analysis Result

\begin{tabular}{|l|l|l|}
\hline Name & Type & Time $(\mathrm{m})$ \\
\hline University & Process & 5856 \\
\hline Place Offer & Task & 1344 \\
\hline Download Date from UCAS & Task & 708 \\
\hline
\end{tabular}

\begin{tabular}{|l|l|l|}
\hline Refuse Offer & Task & 0 \\
\hline Triage Call & Task & 1500 \\
\hline Chat with Applicant & Task & 1431 \\
\hline Send Enrolment Invitation & Task & 163 \\
\hline Decline Offer & Inter. event & \\
\hline Contact Applicant & Task & 57 \\
\hline Process Offer & Task & 489 \\
\hline Upload offer conf. to UCAS & Task & 163 \\
\hline
\end{tabular}

Table 9: Simulation Results of both Processes

\begin{tabular}{|l|l|l|l|l|}
\hline Metric & AS IS & TO BE & Diff. & $\%$ Diff. \\
\hline Time & 57 mins & 0 & 57 mins & $100 \%$ \\
\hline Cost & $£ 12,034$ & $£ 7,251$ & $£ 4,782$ & $49.59 \%$ \\
\hline Complexity & N/A & N/A & N/A & N/A \\
\hline Flexibility & N/A & N/A & N/A & N/A \\
\hline
\end{tabular}

\section{COMPLEXITY \& FLEXIBILITY}

Complexity as earlier defined is the aggregation of logical complexity and structural complexity. Logical complexity (i.e. Control Flow Complexity) is measured by counting the number of decisions in the flow of control in the process model. A low CFC indicates that the process model is easy to understand. Splits in the model add to the CFC number as follows: OR-split with $n$ will add $2^{n-1}$ to the CFC metric, AND-split will add 1 to the CFC metric and XOR-split with $n$ outgoings will add $n$ to the CFC metric of the model [7][31].

$$
\begin{aligned}
& \mathrm{CFC}(\mathrm{BP})= \sum_{\text {AND-split }} \mathrm{CFC}(\mathrm{C})+\sum_{\text {OR-Split }} \mathrm{CFC}(\mathrm{C})+ \\
& \sum_{X O R-\text { Split }} \mathrm{CFC}(\mathrm{C})
\end{aligned}
$$

Where

AND-split $=+n$,

XOR-Split $=+\mathrm{n}$,

OR-Split $=2^{n-1}$

There are 6 OR-splits, 0 AND-splits and 0 XOR-splits in the as-is clearing model, so applying the formulae, we have $\mathbf{2}^{\mathbf{6}-1}$ = 32. While in the to-be there are 4 OR-splits, 1 AND-splits and 0 XOR-splits, so applying the formulae, we have $\left(\mathbf{2}^{\mathbf{4}-1}\right)$ $\mathbf{+ 1}=\mathbf{9}$, implying that there has been an improvement in the logical complexity.

The structural complexity and flexibility measures are obtained from the network projections of both the as-is and to-be clearing processes. Next, we apply the projection rules to reduce the business process models to their network structures.

\subsection{Network Projection of the Process}

The Social Network Visualizer (SocNetV) tool [25] was used to create the network projections as well as to perform the analysis. The network projections are shown in figures 4 and 5. The colored nodes simply show the nodes in the same BPMN lane 


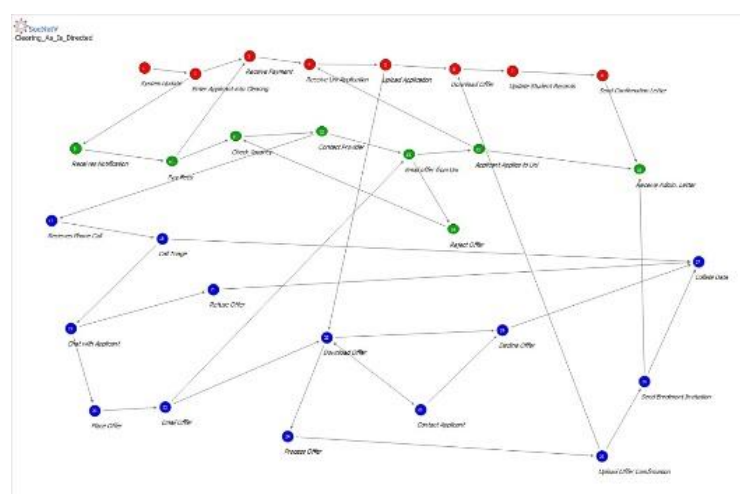

Figure 4. As-Is Downscaled Network

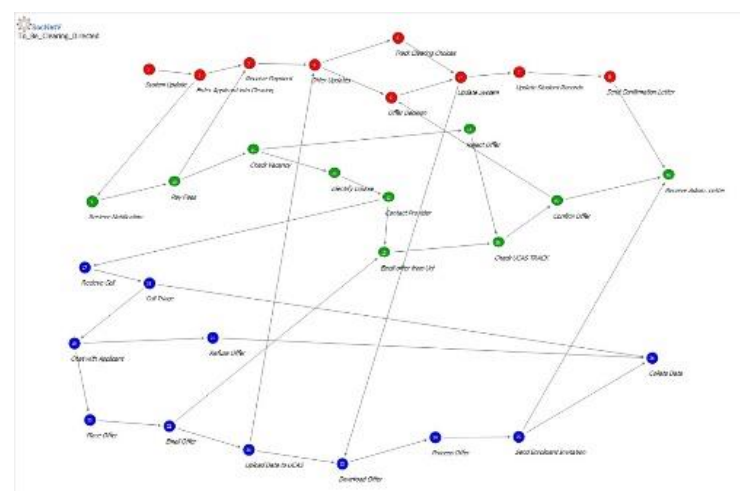

Figure 5. To-Be Downscaled Network

The results obtained from the analysis is shown in table 10 .

Table 10: Data from Directed Network Analysis

\begin{tabular}{|l|l|l|l|}
\hline Process Model & No of Nodes & Density & Diameter \\
\hline As Is Process & 29 & 0.051 & 10 \\
\hline To Be Process & 30 & 0.046 & 12 \\
\hline
\end{tabular}

Applying the formula for the overall complexity:

$C=\frac{c f c+(\mathrm{s}+\mathrm{d}) / 2}{2}$

$\mathrm{C}_{\mathrm{as}-\mathrm{is}}=\frac{32+(29+10) / 2}{2}=25.75, \mathrm{C}_{\mathrm{to}-\mathrm{be}}=\frac{9+(30+12) / 2}{2}=15$

$\mathrm{F}_{\text {as-is }}=1 / \mathrm{D}=1 / 0.051=19.60, \mathrm{~F}_{\text {to-be }}=1 / \mathrm{D}=1 / 0.046=21.74$

The calculations above show that the to-be process model is less complex than the as-is process model and there is an increased flexibility in the to-be process model. Overall, there is a visible improvement in the to-be process model as displayed in table 11 and visualized figure 6.

Table 11: Evaluation Outcome

\begin{tabular}{|l|l|l|l|l|}
\hline Metric & AS IS & TO BE & Diff. & $\%$ Diff. \\
\hline Time & $1071 \mathrm{~s}$ & 0 & $1071 \mathrm{~s}$ & $100 \%$ \\
\hline Cost & $£ 12,034$ & $£ 7,251$ & $£ 4,782$ & $49.59 \%$ \\
\hline
\end{tabular}

\begin{tabular}{|l|l|l|l|l|}
\hline Complexity & 25.75 & 15 & 10.75 & $52.76 \%$ \\
\hline Flexibility & 19.60 & 21.74 & 2.14 & $10.35 \%$ \\
\hline
\end{tabular}

\section{CONCLUSION AND FUTURE WORK}

Our aim was to identify measurable concepts that could provide quantitative metrics and visualized process improvement both at design and execution stages. We employed a hybrid approach by using complex network analysis techniques to determine process improvement at the design stage and simulation techniques at the execution stage. Both techniques were applied to an as-is and to-be UK HEI clearing process to measure improvement. A custommade scaled Reversed-Y Quadrangle was used to track and visualize improvements in four dimensions.

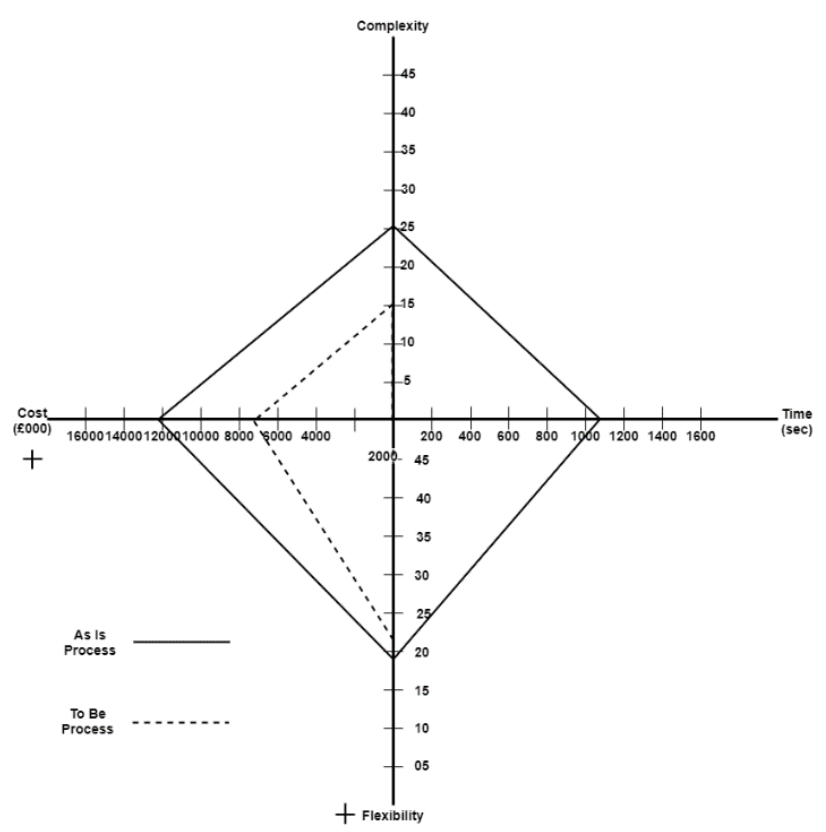

Figure 6. Reversed-Y Quadrangle for the Processes

While it may be easy to predict the outcome of the simulation in terms of cost and time, the structural properties of the process models can be obscure. We have demonstrated that complex network analysis (CNA) techniques can contribute towards improving and measuring business processes. In terms of complexity, the to-be process is less logically complex than the as-is process according to the CFC analysis. This is beneficial because there is less decision making in the process resulting in a decrease in delays and throughput time. However, in terms of structural complexity the as-is process is favoured over the to-be process. This is a result of the to-be process having a higher structural diameter which translates into less efficient information transport between the nodes. Since a more distributed system requires more attention to be placed on information access, relevant improvement heuristics (such as integration between the UCAS and University systems and/or 
introduction of a document management system) could be introduced to enhance the efficiency of the process. In terms of the overall complexity the to-be clearing process is significantly less complex than the as-is clearing process.

The density metric indicates the amount of connections in a network. It is a measure of flexibility, the higher the density the lower the flexibility. From figure 6 we can see the to-be process is more flexible and efficient than the as-is process. Further work will see an investigation into the applicability of other types of networks such as undirected and weighted directed networks, and if applicable, further projections can be considered. Future work will explore the interpretation and relevance of complex network analysis metrics to business process models to provide further insight into its macrostructure.

\section{REFERENCES}

[1] W. M. P. van der Aalst, "Business Process Management: A Comprehensive Survey," ISRN Softw. Eng., 2013, doi: 10.1155/2013/507984.

[2] Z. Irani, V. Hlupic, and G. M. Giaglis, "Guest editorial: Business process reengineering: An analysis perspective," Int. J. Flex. Manuf. Syst., vol. 14, no. 1, pp. 510, 2002, doi: 10.1023/A:1013868430717.

[3] P. Boekhoudt, H. Jonkers, and M. Rougoor, "Graph-based analysis of business process models," in Mathematics and Computers in Modern Science, Proc. of the WSES/MIUE/HNA International Conference, 2000, pp. 227-235.

[4] L. S. González, F. G. Rubio, F. R. González, and M. P. Velthuis, "Measurement in business processes: A systematic review," Bus. Process Manag. J., 2010, doi: 10.1108/14637151011017976.

[5] L. Sánchez-González, F. Ruiz, F. García, and M. Piattini, "Business process model improvement based on measurement activities," in ENASE 2011 - Proceedings of the 6th International Conference on Evaluation of Novel Approaches to Software Engineering, 2011.

[6] W. Khlif, L. Makni, N. Zaaboub, and H. BenAbdallah, "Quality metrics for business process modeling," in Proceedings of the 9th WSEAS International Conference on Applied Computer Science, ACS '09, 2009.

[7] V. G. and R. Laue, "Complexity Metrics for Business Process Models."

[8] M. Dumas, M. La Rosa, J. Mendling, and H. A. Reijers, Fundamentals of Business Process Management. Berlin Heidelberg: Springer, 2013.

[9] Y. Yang, X. Hao, and J. Luo, "Traffic Impact Simulation for Road Construction Project," TELKOMNIKA Indones. J. Electr. Eng., 2012, doi: 10.11591/telkomnika.v10i8.1657.

[10] E. Rolón, F. Ruiz, F. García, and M. Piattini, "Applying Software Metrics to evaluate Business Process Models," CLEI Electron. J., 2006, doi: 10.19153/cleiej.9.1.5.
[11] E. R. Aguilar, F. Ruiz, F. García, and M. Piattini, "Evaluation measures for business process models," in Proceedings of the ACM Symposium on Applied Computing, 2006.

[12] J. Mendling, "Detection and prediction of errors in EPC business process models.," University of Economics and Business Administration, Vienna, 2007.

[13] S. Bisogno, A. Calabrese, M. Gastaldi, and N. Levialdi Ghiron, "Combining modelling and simulation approaches: How to measure performance of business processes," Bus. Process Manag. J., 2016, doi: 10.1108/BPMJ-02-2015-0021.

[14] J. Oukharijane, F. Yahya, K. Boukadi, and H. Ben Abdallah, "Towards an Approach for the Evaluation of the Quality of Business Process Models," in Proceedings of IEEE/ACS International Conference on Computer Systems and Applications, AICCSA, 2019, doi: 10.1109/AICCSA.2018.8612811.

[15] J. Cardoso, J. Mendling, G. Neumann, and H. A. Reijers, "A discourse on complexity of process models," in Lecture Notes in Computer Science (including subseries Lecture Notes in Artificial Intelligence and Lecture Notes in Bioinformatics), 2006.

[16] T. J. Mccabe, "A Complexity Measure," IEEE Trans. Softw. Eng., 1976, doi: 10.1109/TSE.1976.233837.

[17] I. Vanderfeesten, H. A. Reijers, J. Mendling, W. M. P. Van Der Aalst, and J. Cardoso, "On a quest for good process models: The cross-connectivity metric," in Lecture Notes in Computer Science (including subseries Lecture Notes in Artificial Intelligence and Lecture Notes in Bioinformatics), 2008, doi: 10.1007/978-3-540-69534-9_36.

[18] I. Vanderfeesten, J. Cardoso, and H. A. Reijers, "A weighted coupling metric for business process models," in CEUR Workshop Proceedings, 2007.

[19] J. Mendling, "Testing Density as a Complexity Metric for EPCs," Analysis, 2006.

[20] M. E. J. Newman, Networks. Oxford University press, 2010.

[21] B. Ferdinandy, "What's the difference between a graph and a network?" https://bence.ferdinandy.com/2018/05/27/whats-thedifference-between-a-graph-and-a-network/.

[22] M. Jamali and H. Abolhassani, "Different aspects of social network analysis," in Proceedings - 2006 IEEE/WIC/ACM International Conference on Web Intelligence (WI 2006 Main Conference Proceedings), WI'06, 2007, doi: 10.1109/WI.2006.61.

[23] N. R. Hassan, "Using social network analysis to measure IT-enabled business process performance," Inf. Syst. Manag., 2009, doi: 10.1080/10580530802557762.

[24] H. Brand, N., Van der Kolk, "Workflow analysis and design," Deventer: Kluwer Bedrijfswetenschappen., 1995.

[25] "Social Network Visualizer." https://socnetv.org/. [26] W. M. P. Van der Aalst, M. Weske, and A. H. M. ter Hofstede, "Business Porcess Management: A Survey," Conference on Business Process Management. 2003. 
[27] M. P. Vukšić, V.B., Bach and KatarinaTomičićPupek, "Process Performance Management in Higher Education Regular Paper," 2014.

[28] O. Fakorede, P. Davies, and D. Newell, "Using business process modelling to improve student recruitment in UK higher education," in Lecture Notes in Business Information Processing, 2019, doi: 10.1007/978-3-03004849-5_11.
[29] L. Makni, W. Khlif, N. Z. Haddar, and H. Benabdallah, "A Tool for Evaluating the Quality of Business Process Models Overview on current metrics for BPM," Inform. 2010 Bus. Process Serv. Sci. - Proc. ISSS BPSC P177, 230-242 (2010)., 2010.

[1] 